\title{
Protection of Galvanized Steel with Silanes: Its Comparison with Chromium(VI)
}

\author{
P.R. Seré, C. Deyá, W.A. Egli, C.I. Elsner, and A.R.Di Sarli
}

(Submitted July 29, 2013; in revised form September 16, 2013; published online October 18, 2013)

\begin{abstract}
The corrosion behavior of hot dip galvanized steel (HDGS) pre-treated with mercaptopropyltrimethoxysilane and a commercial sulfur-bearing silane was studied. Electrochemical polarization, electrochemical impedance spectroscopy, and electrochemical noise tests showed that silane coatings have a corrosion protection performance similar to the usual hexavalent chromium HDGS passivation treatments. It is also evident that the silane films protect the zinc surface through the formation of an isolating barrier. Through voltamperometric studies it was possible to define an electrochemical porosity of the protective coatings. Based on copper sulfate tests and electrochemical porosity results the films protection capability was evaluated, showing that silane treatments have similar or even better protection performance than standard chromium passivation.
\end{abstract}

Keywords cyclic voltammetry, electrochemical impedance spectroscopy, metal coatings, polymer coatings, scanning electron microscopy, zinc

\section{Introduction}

Conversion treatments based on $\mathrm{Cr}^{6+}$ have been used for many years for protecting the galvanized steel against corrosion during storage and use. Despite they are very efficient, the $\mathrm{Cr}^{6+}$ high toxicity and carcinogenic nature (Ref 1) creates the necessity to look for new environment-friendly alternatives. In this way, pre-treatment with functionalized silane solutions rise as an alternative, although they do not have the self-healing effect afforded by the hexavalent chromium coatings, they are neither toxic nor pollutant, have good thermal stability and are more resistant to erosion (Ref 2). Silane coatings protects the substrate only by barrier effect (Ref $3-7$ ) so, the protective capacity depends not only on the film thickness and porosity but also on the silane nature. The presence of hydrophobic or hydrophilic chains in the silane structure may control the rate of water diffusion through the coating film. Besides, characteristics of the substrate such as roughness, metal structure, etc. must be taken into account since the adhesion of the silane to the metal could be favored or not.

The most common reaction of the silanes is its hydrolysis, as for example:

P.R. Seré, C. Deyá, W.A. Egli, C.I. Elsner, and A.R.Di Sarli, Centro de Investigación y Desarrollo en Tecnología de Pinturas, CIDEPINT, CICPBA-CONICET, Av. $52 \mathrm{~s} / \mathrm{n}$ entre 121 y 122, B1900AYB La Plata, Argentina. Contact e-mail: anelpire3@cidepint.gov.ar.

$$
\begin{aligned}
\mathrm{R} & -\left(\mathrm{CH}_{2}\right)_{n}-\mathrm{Si}\left(\mathrm{OR}^{\prime}\right)_{3}+3 \mathrm{H}_{2} \mathrm{O} \\
& \rightarrow \mathrm{R}-\left(\mathrm{CH}_{2}\right)_{n}-\mathrm{Si}(\mathrm{OH})_{3}+3 \mathrm{R}^{\prime} \mathrm{OH}
\end{aligned}
$$

where $\mathrm{R}$ is a group such as $-\mathrm{SH},-\mathrm{OH},-\mathrm{CHOCH}_{2},-\mathrm{COOH}$, $-\mathrm{NH}_{2}$, etc., and $\mathrm{R}^{\prime}$ are $-\mathrm{CH}_{3}$ and $-\mathrm{CH}_{2} \mathrm{CH}_{3}$. Reaction (1) generates highly reactive silanol molecules, which react with the oxides and/or hydroxides present on metallic surfaces and form strong silanol-metal-oxygen bonds (Ref 8) producing a very thin film of silane (Ref 9,10$)$.

In the present work, the corrosion behavior of hot-dip galvanized steel (HDGS) pre-treated with either $\gamma$-mercaptopropyltrimethoxysilane (MTMO) or a sulfur-bearing commercial silane (SIVO) was studied (Ref 11). These silanes are free of heavy metals, fluoride and/or organic solvents, have low volatility and high reactivity. The morphology of the silanes films formed on the HDGS surface was studied by scanning electron microscopy (SEM) and optical microscopy (OM). The film composition was characterized by electron dispersive $\mathrm{x}$-ray spectroscopy (EDXS), while their protective behavior was evaluated by cyclic voltammetry $(\mathrm{CV})$, polarization curves (PC), electrochemical impedance spectroscopy (EIS) and electrochemical noise (EN). The obtained results were compared with those of the control samples (HDGS chromate-free samples and HDGS covered with conventional $\mathrm{Cr}^{6+}$ processes).

\section{Experimental Details}

\subsection{Samples Preparation}

The samples were cut from commercial HDGS $(7.5 \mathrm{~cm} \times$ $10.0 \mathrm{~cm} \times 0.07 \mathrm{~cm})$ panels. The chromate conversion coating was eliminated by polishing with abrasive emery cloth. The complete elimination of the chromium was verified with 1.5diphenylcarbohidrazyde according to the ASTM D 2092 standard. The roughness values for unpolished and polished samples presented in Table 1 put in evidence that no significant changes were observed on the surface topography. Average 
$\left(R_{\mathrm{a}}, R_{\mathrm{zd}}\right)$ and total $\left(R_{\mathrm{t}}\right)$ roughness were determined according to DIN 4768 and ISO/JIS 4287/1 standards, respectively.

The samples were dipped in the silane solutions, dried using warm air and cured in an oven following the conditions shown in Table 2. The MTMO solution was prepared adding 4\% v/v MTMO to a distilled water/methanol (3:2 v/v) solution (the $\mathrm{pH}$ was adjusted to 4 with acetic acid) (Ref 8 ), while $50 \% \mathrm{v} / \mathrm{v}$ SIVO was diluted in distilled water.

Some polished HDGS chromate-free samples $(\mathrm{ZN})$ and some standard HDGS samples with $\mathrm{Cr}^{6+}$ layer $(\mathrm{Cr}(\mathrm{VI}))$, were reserved as reference coupons.

\subsection{Immersion in Copper Sulfate Solution Test}

Passivation and silane films porosity and continuity was characterized with immersion in copper sulfate solution (ASTM A-239 standard). The test solution was prepared dissolving $36 \mathrm{~g}$ of $\mathrm{CuSO}_{4} \cdot 5 \mathrm{H}_{2} \mathrm{O}$ in $100 \mathrm{~mL}$ of distilled water and neutralized with $\mathrm{Cu}(\mathrm{OH})_{2}$. The samples were immersed in the solution for $10 \mathrm{~s}$ and then washed with distilled water. The porosity of the barrier film was evaluated by visual observation

Table 1 Effect of polishing on sample surface roughness

\begin{tabular}{lcc}
\hline Parameter, $\boldsymbol{\mu m}$ & Unpolished & Polished \\
\hline$R_{\mathrm{a}}$ & 0.59 & 0.53 \\
$R_{\mathrm{zd}}$ & 2.93 & 3.09 \\
$R_{\mathrm{t}}$ & 4.84 & 4.71 \\
\hline
\end{tabular}

Table 2 Silane pretreatment conditions

\begin{tabular}{lcccc}
\hline Silane & $\% \mathbf{V} / \mathbf{V}$ & $\begin{array}{c}\text { Immersion } \\
\text { time, } \mathbf{m i n}\end{array}$ & $\begin{array}{c}\text { Curing } \\
\text { time, } \mathbf{m i n}\end{array}$ & $\begin{array}{c}\text { Curing } \\
\boldsymbol{T},{ }^{\circ} \mathbf{C}\end{array}$ \\
\hline MTMO & 4 & 1 & 10 & 80 \\
SIVO & 50 & 0.5 & 1200 & 25 \\
\hline
\end{tabular}

and $\mathrm{OM}$ in relation with the amount of zinc active sites where $\mathrm{Cu}^{0}$ was deposited.

\subsection{Cyclic Voltammetry and Polarization Curves}

As recommended by Tits et al. Ref $12, \mathrm{CV}$ was performed in aerated borate solution $\left(35 \mathrm{~g} / \mathrm{L}\right.$ of $\mathrm{H}_{3} \mathrm{BO}_{3}$ and $40 \mathrm{~g} / \mathrm{L}$ of $\mathrm{Na}_{2} \mathrm{~B}_{4} \mathrm{O}_{7} \cdot 10 \mathrm{H}_{2} \mathrm{O}$ ) from -1500 to $0 \mathrm{mV}$ versus saturated calomel electrode (SCE), with a scan rate of $100 \mathrm{mV} / \mathrm{s}$. In this electrolyte, the current density curves for zinc electrodes showed a dissolution anodic peak followed by a passive region. Integration of this peak gave an anodic charge proportional to the active $\mathrm{Zn}$ surface area.

Polarization curves were obtained in $0.05 \mathrm{~mol} / \mathrm{L} \mathrm{NaCl}$ solution at $(22 \pm 1){ }^{\circ} \mathrm{C}$ at a potential scan rate of $0.166 \mathrm{mV} / \mathrm{s}$ and $\pm 50 \mathrm{mV}$ from the open circuit potential (OCP). The working electrode (WE) area was $15.9 \mathrm{~cm}^{2}$. A Pt ring of great area and a SCE were used as counter and reference electrode, respectively. The corrosion current density $\left(j_{\text {corr }}\right)$ and the related potential corrosion $\left(E_{\text {corr }}\right)$ were determined by linear regression of the $(E)$ versus $\log (j)$ plot in the potential range OCP $\pm 10 \mathrm{mV}$. The polarization resistance $\left(R_{\mathrm{p}}\right)$ was obtained by linear regression of $(E)$ versus $(j)$ at which no significant amount of corrosion products were formed (Ref 13). Before each run, the electrodes were immersed in the electrolyte, until stable OCP readings were obtained. CV and PC were obtained with a Potentiostat/Galvanostat PAR 273A controlled by CorrWear ${ }^{\circledR}$ software.

\subsection{Electrochemical Impedance Spectroscopy (EIS)}

To carry out the impedance measurements, a cylindrical clamp-on acrylic cell was positioned on the samples, defining a surface area of $15.9 \mathrm{~cm}^{2}$ with a rubber ring. A Pt-mesh was used as counter electrode and a SCE as reference. The samples were exposed to $0.05 \mathrm{~mol} / \mathrm{L} \mathrm{NaCl}$ solution at $(22 \pm 1){ }^{\circ} \mathrm{C}$ and the EIS scans were performed after 1, 2, 5, 10 , and $16 \mathrm{~h}$ of immersion. Impedance spectra were obtained

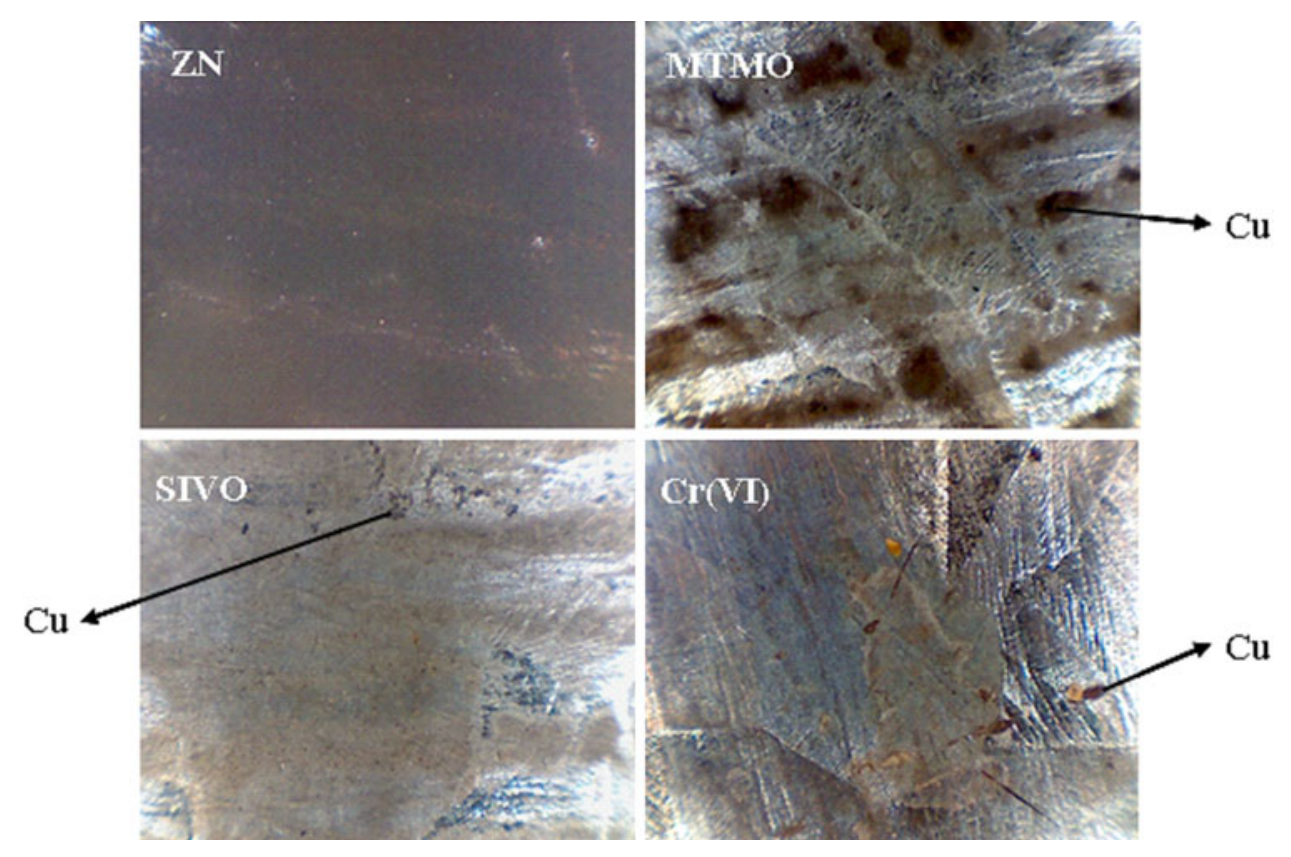

Fig. 1 OM images (x200) of blanks and pre-treated samples exposed $10 \mathrm{~s}$ to $\mathrm{Cu}^{2+}$ solution 
in the potentiostatic mode at the OCP using a sinusoidal signal with $15 \mathrm{mV}$ peak to peak amplitude, using a Solartron 1255 FRA $^{\circledR}$ coupled with an Impedance Potentiostat-Galvanostat Solartron $1286 \mathrm{EI}^{\circledR}$, and both controlled by the Zplot ${ }^{\circledR}$ software.

\subsection{Electrochemical Noise (EN)}

The setup for EN measurements was composed by two identical WE made of the same sample and a SCE. Both WE were connected through a resistor with low impedance (1.2 $\Omega$ ) and the current noise was measured through voltage fluctuation across the resistor, so that interferences from the electronic circuitry are diminished (Ref 14). The potential was measured between one of the WE and the SCE. The edges of the
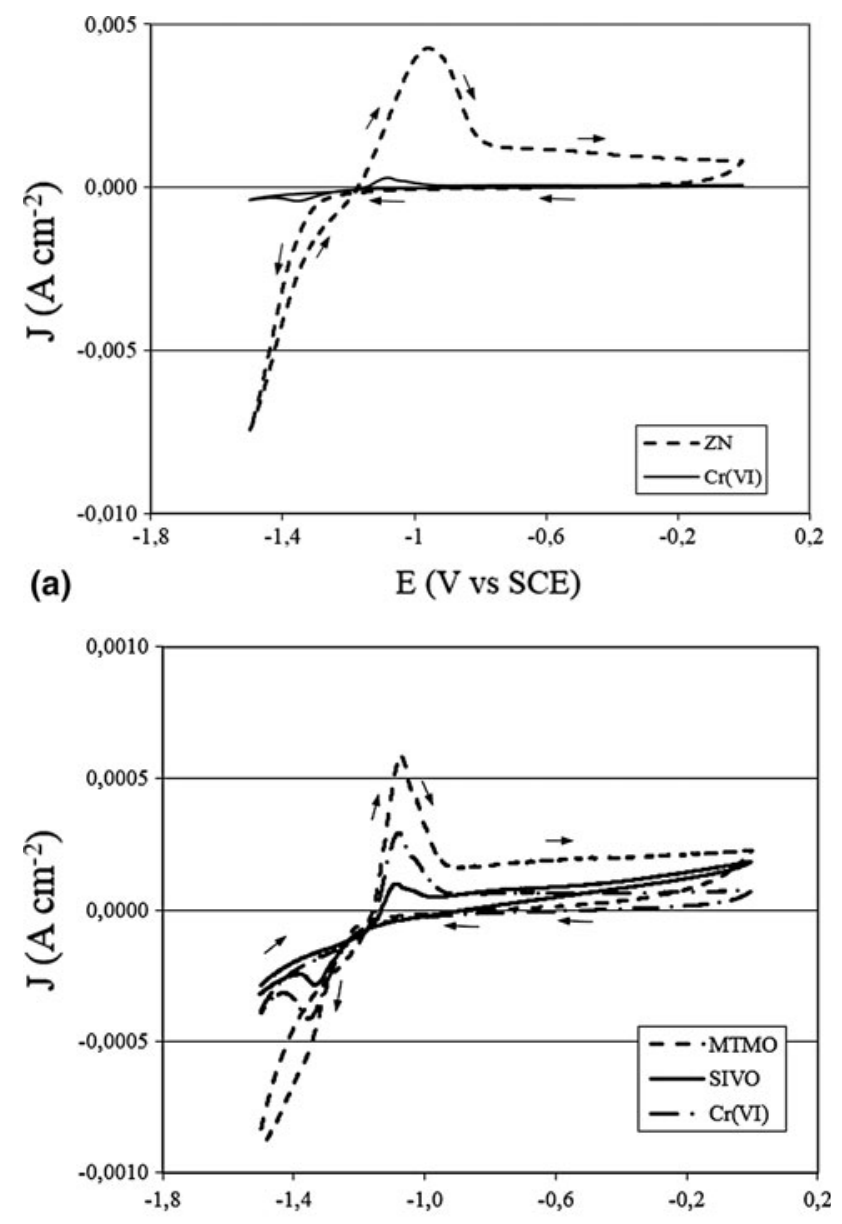

(b)

E (V vs SCE)

Fig. 2 Cyclic voltammetry (a) ZN and $\mathrm{Cr}(\mathrm{VI})$ samples, (b) MTMO, SIVO, and $\mathrm{Cr}(\mathrm{VI})$ samples

Table 3 FPi estimation for CrVI and silane-treated samples

\begin{tabular}{lcc}
\hline Sample & $\boldsymbol{Q}, \mathbf{C} / \mathbf{c m}^{\mathbf{2}}$ & $\mathbf{F P}^{\boldsymbol{i}}$ \\
\hline ZN & $8.44 \times 10^{-3}$ & 100 \\
MTMO & $6.32 \times 10^{-4}$ & 7.49 \\
SIVO & $8.82 \times 10^{-5}$ & 1.04 \\
Cr(VI) & $3.46 \times 10^{-4}$ & 4.10 \\
\hline
\end{tabular}

specimens were isolated with wax leaving a WE surface area of $38 \mathrm{~cm}^{2}$. The three electrodes were immersed in $0.05 \mathrm{~mol} / \mathrm{L}$ $\mathrm{NaCl}$ solution at $(22 \pm 1){ }^{\circ} \mathrm{C}$.

EN raw data were acquired with a NICOLET 310 digital oscilloscope and the corresponding software 310 RSWFT $^{\circledR}$. Adequate filtering was provided just to eliminate undesirable line signals (Ref 15-17). The sensitivity of the measuring device in the $E$-scale was $100 \mu \mathrm{V}$ and $100 \mathrm{nA}$ in the current measurements. Sampling time was $800 \mathrm{~s}$ at a frequency of $5 \mathrm{~Hz}$, figures usually used to study corroding systems (Ref 1517). Mean values of raw data of the coupling current and the potential were plotted. Statistical analysis of each time series was performed and the noise resistance $\left(R_{\mathrm{n}}\right)$ was calculated as the quotient $R_{\mathrm{n}}=\sigma_{\mathrm{E}} / \sigma_{\mathrm{i}}$, where $\sigma_{\mathrm{E}}$ is the dispersion of the potential data while $\sigma_{\mathrm{i}}$ is the dispersion of the current data (Ref 16-18). The DC trend was removed to perform $R_{\mathrm{n}}$ calculation by the procedure described by Tan et al. Ref 18 , and each set of data was statistically controlled to verify that they were normally distributed (Ref 19).

\subsection{Observation and Characterization of the Silane Films}

Silane films were observed by SEM using a FEI Quanta $200^{\circledR}$ microscope with electron detector Apollo $40^{\circledR}$, and by OM with a portable USB OM device (DigiView). The film composition was determined by energy dispersive $\mathrm{x}$-ray spectroscopy (EDXS) using a detector EDAX ${ }^{\circledR}$.

\section{Results and Discussion}

The active zinc surface area exposed to the $\mathrm{Cu}^{2+}$ solution of ZN, MTMO, SIVO, and Cr(VI) samples was evaluated. In the case of ZN samples, copper was homogeneously deposited on the entire surface area, certifying that $100 \%$ of geometric electrode area was active zinc. On MTMO, SIVO, and Cr(VI) samples, copper deposition took place only where the corresponding film barrier was absent (pores). The results revealed a number of pores in MTMO pre-treated panels higher than in $\mathrm{Cr}(\mathrm{VI})$ and SIVO ones, which showed similar results with few and isolated points of deposited copper (Fig. 1). From this qualitative essay it was possible to establish the following order regarding film porosity (FP):

$$
\mathrm{FP}_{\mathrm{ZN}} \gg \mathrm{FP}_{\mathrm{MTMO}} \gg \mathrm{FP}_{\mathrm{Cr}(\mathrm{VI})} \sim \mathrm{FP}_{\mathrm{SIVO}}
$$

$\mathrm{CV}$ of $\mathrm{ZN}$ samples showed one anodic peak at $\approx-1.0$ $\mathrm{V}$ (SCE) (Fig. 2a) followed by a passive region (Ref 12). This peak corresponds to the formation of a $\mathrm{ZnO}$ or $\mathrm{Zn}(\mathrm{OH})_{2}$ film that blocks the active $\mathrm{Zn}$ surface promoting the passivation process. During the reverse cathodic scan, the oxide-hydroxide film is reduced. $\mathrm{H}_{2}$ evolution and $\mathrm{O}_{2}$ reduction reactions also contribute to increase the current density in the cathodic peak (Ref 20). In Fig. 2a, the curves for $\mathrm{ZN}$ and $\mathrm{Cr}(\mathrm{VI})$ samples are compared. Lower current densities are observed in the case of $\mathrm{Cr}(\mathrm{VI})$ samples due to the presence of the chromate passive film which covers and partially blocks the $\mathrm{Zn}$ active surface. In Fig. 2b, the curves for silane pre-treated and $\mathrm{Cr}$ (VI) samples are shown. It can be seen that anodic peak in SIVO samples is smaller than in $\mathrm{Cr}(\mathrm{VI})$ samples, indicating that this silane treatment hinders the zinc electrochemical active area more 

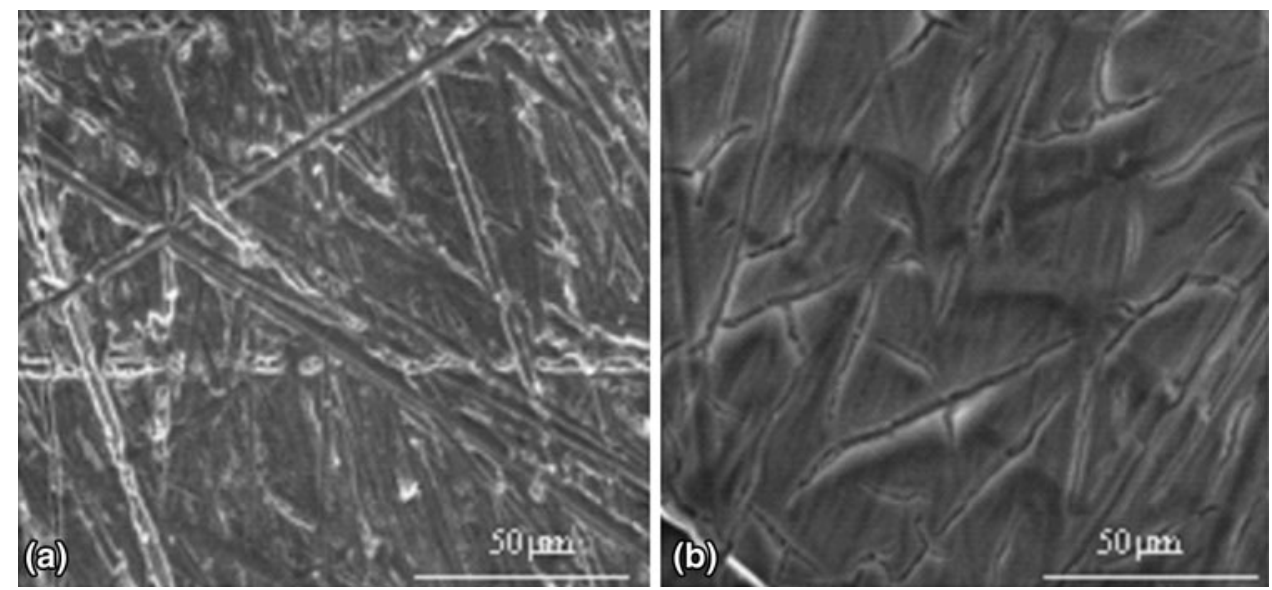

Fig. 3 SEM images of (a) MTMO, (b) SIVO pre-treated surfaces

Table 4 EDS compositions for silane pretreated samples

\begin{tabular}{lcc}
\hline Wt.\% & MTMO & SIVO 160 \\
\hline $\mathrm{Si}$ & 1.18 & 13.24 \\
$\mathrm{Zn}$ & 76.71 & 16.69 \\
$\mathrm{Si} / \mathrm{Zn}$ & 0.015 & 0.793 \\
\hline
\end{tabular}

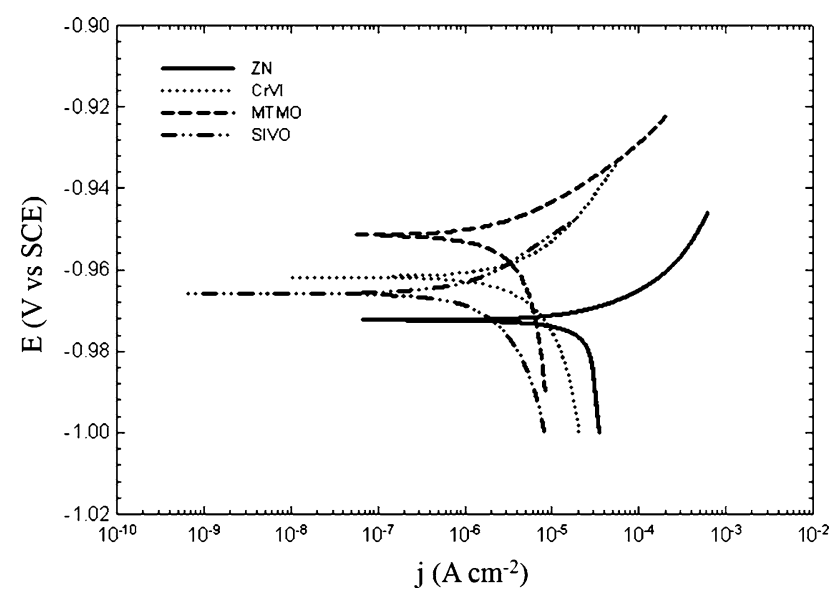

Fig. 4 Polarization curves of blanks and pre-treated samples in $0.05 \mathrm{~mol} / \mathrm{L} \mathrm{NaCl}$

efficiently than the chromate conversion film. On the other hand, the MTMO sample shows similar behavior as $\mathrm{Cr}(\mathrm{VI})$.

The silane film protects the zinc coating against corrosion, through a barrier mechanism, so that the higher the film uniformity, the higher the protective capacity (Ref 21).

Based on copper sulfate solution immersion tests, it can be considered that $\mathrm{ZN}$ samples have its whole geometric area electrochemically active, while silanes pre-treated, and $\mathrm{Cr}(\mathrm{VI})$ ones, have partially blocked surfaces with reduced active area. In this sense, FP can be defined as:

$\mathrm{FP}^{i}=A_{\mathrm{Zn}}^{i} / A^{\mathrm{o}} * 100$

where $A_{\mathrm{Zn}}^{i}$ is the free active zinc area on the $(i)$ pre-treated sample, and $A^{\circ}$ is the geometric area of the sample. The evaluation
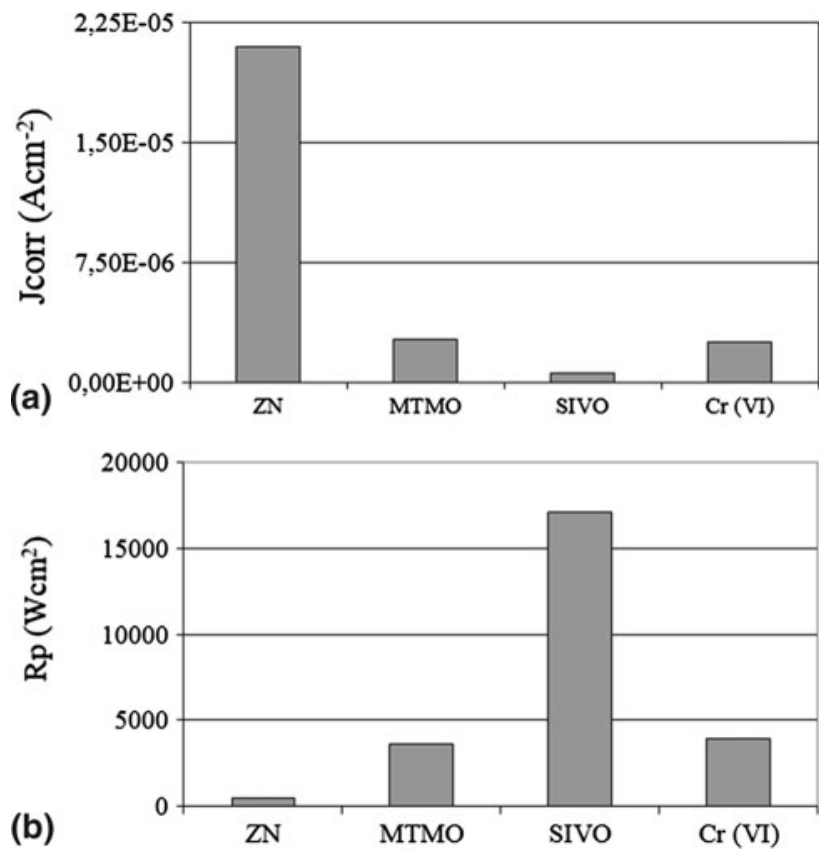

Fig. 5 (a) $J_{\text {corr }}$ and (b) $R_{\mathrm{p}}$ of blanks and pre-treated samples immersed in $0.05 \mathrm{~mol} / \mathrm{L} \mathrm{NaCl}$

of $A_{\mathrm{Zn}}^{i}$ for the different samples could be performed by taking into account the $\mathrm{CV}$ curves. From the area under the anodic peak, it is possible to evaluate the charge density $\left[Q\left(\mathrm{Ccm}^{-2}\right)\right]$ related with the anodic dissolution of zinc. In the case of $\mathrm{ZN}$ samples, it is possible to evaluate $Q^{\circ}$, associated to a completely free zinc surface, while for the other samples the charge density will be $Q^{i}$, corresponding to the anodic charge associated to the zinc active area of film porosity.

By definition:

$Q^{i}=q_{\mathrm{Zn}}^{i} / A^{\circ}$

where $q_{\mathrm{Zn}}^{i}$ is the charge in $C$ for the anodic process on the active free-zinc surface of the $(i)$ sample and it can be shown as related to $Q^{\circ}$ through:

$q_{\mathrm{Zn}}^{i}=Q^{\circ} * A_{\mathrm{Zn}}^{i}$

Combining (Eq 2) and (Eq 3), 
$Q^{i}=Q^{\mathrm{o}} * A_{\mathrm{Zn}}^{i} / A^{\mathrm{o}}$

From (Eq 1) and (Eq 4) it is possible to obtain an electrochemical estimation of FP as follows:

$\mathrm{FP}^{i}=Q^{i} / Q^{\mathrm{o}} * 100$

In Table 3 are shown the $\mathrm{FP}^{i}$ results for $\mathrm{Cr}(\mathrm{VI})$ and the silanes pre-treated samples.

According to these results the three protective films have very low porosity values, and the film with the lowest porosity is the one with SIVO. These results are in accordance with those obtained by the copper sulfate immersion test, but $\mathrm{FP}^{i}$

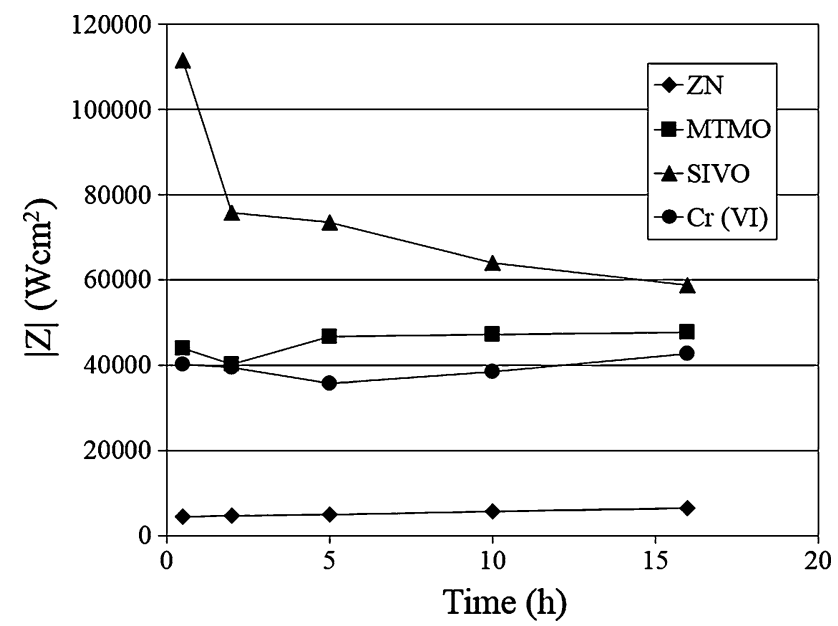

Fig. 6 IZI time evolution of blanks and pre-treated samples immersed in $0.05 \mathrm{~mol} / \mathrm{L} \mathrm{NaCl}$
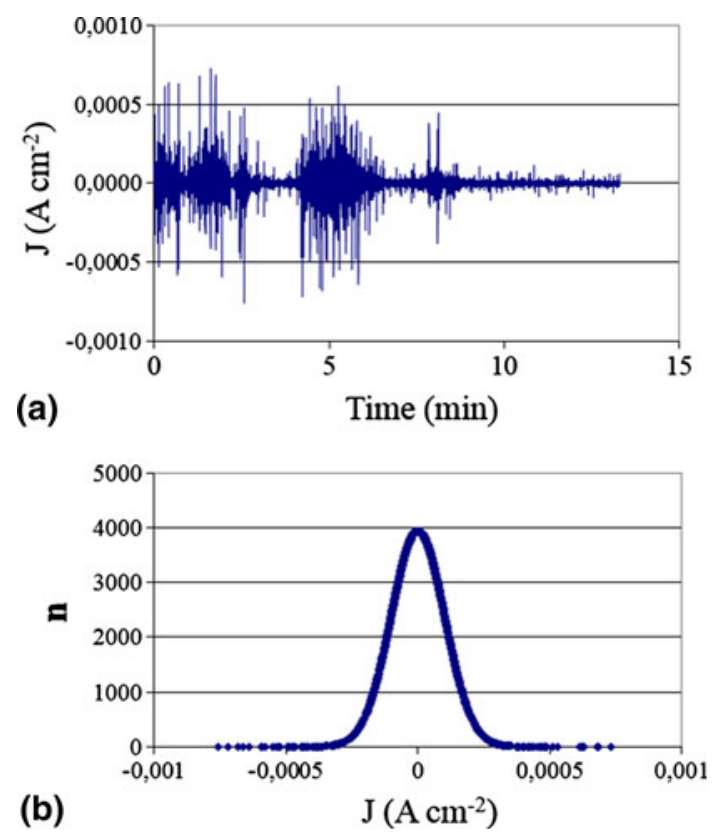

Fig. 7 (a) Current electrochemical noise spectra obtained for $\mathrm{Cr}(\mathrm{VI})$ sample after $60 \mathrm{~min}$ of immersion in $0.05 \mathrm{~mol} / \mathrm{L} \mathrm{NaCl}$, (b) Gauss distribution of the data allows to see the differences between $\mathrm{Cr}(\mathrm{VI})$ and SIVO, not detected by the cupper sulfate test. From these results it was possible to establish the following ranking from the $\mathrm{FP}^{i}$ comparison:

$$
\mathrm{FP}_{\mathrm{ZN}} \gg \mathrm{FP}_{\mathrm{MTMO}}>\mathrm{FP}_{\mathrm{Cr}(\mathrm{VI})}>\mathrm{FP}_{\mathrm{SIVO}}
$$

SEM images of the silane pre-treated samples are shown in Fig. 3. In the case of MTMO, (Fig. 3a), the film is not clearly seen. On the other hand, in the case of SIVO, (Fig. 3b) a film covering the zinc surface is observed and it presents a dense and quite compact structure.

According to Table 4 data, the $\mathrm{Si} / \mathrm{Zn}$ ratio in weight percent, obtained by EDXS, is higher for SIVO than for MTMO, and this is probably due to the thicker and more compact film formed on the first one ( $\operatorname{Ref} 8)$.

The films morphology and composition as well as the CV results allow inferring that SIVO would provide a better protective efficiency, i.e., barrier effect to the ionic flux, because it gives rise to a more compact film than the formed by the MTMO.

Figure 4 exhibits the PC of the tested samples exposed to $\mathrm{NaCl}$ solution. The OCP values for non-treated and pre-treated

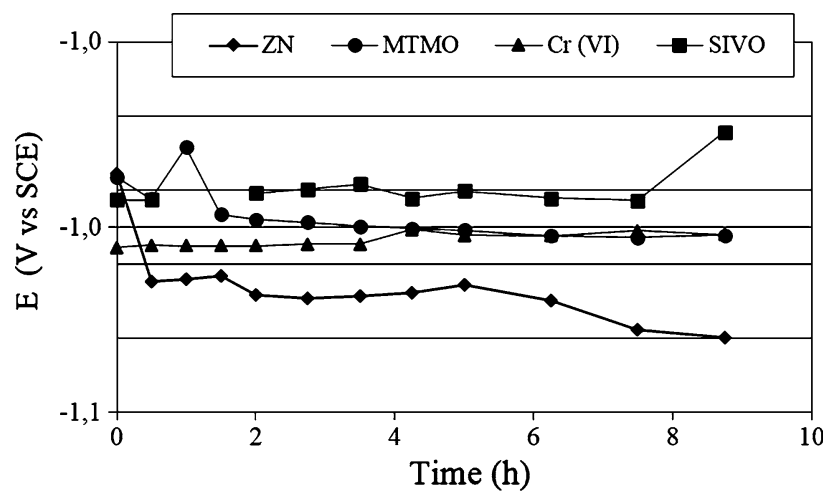

Fig. 8 Corrosion potential of blanks and pre-treated samples against time

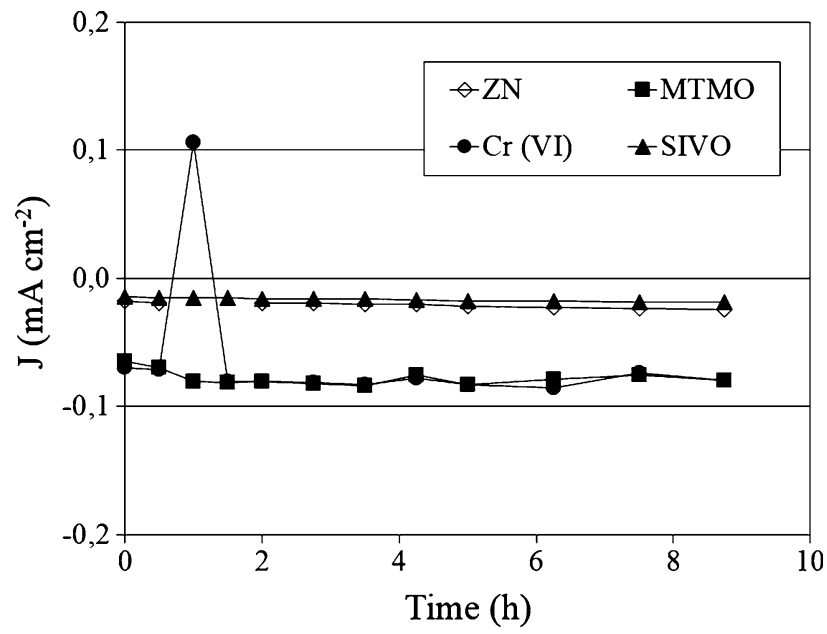

Fig. 9 Coupling current of blanks and pre-treated samples against time 
samples were in the range of -0.97 and $-0.96 \pm 0.01 \mathrm{~V}(\mathrm{SCE})$, respectively. From these values no significant changes could be detected as a consequence of the treatment. The corrosion current $\left(j_{\text {corr }}\right)$ and the polarization resistance $\left(R_{\mathrm{p}}\right)$ values, calculated from the PC, may be used to evaluate the corrosion behavior of pre-treated and non-treated samples. The experimental results are summarized in Fig. 5, where $j_{\text {corr }}$ and $R_{\mathrm{p}}$ values of SIVO and MTMO samples were compared to the reference ones, $\mathrm{ZN}$ and $\mathrm{Cr}(\mathrm{VI})$. As expected, $\mathrm{ZN}$ samples were the most active, showing higher $j_{\text {corr }}$ (Fig. 5a) and lower $R_{\mathrm{p}}$ (Fig $5 \mathrm{~b}$ ) values. All the applied treatments produced a decrease in the electrochemical reactivity of the coating, being SIVO the

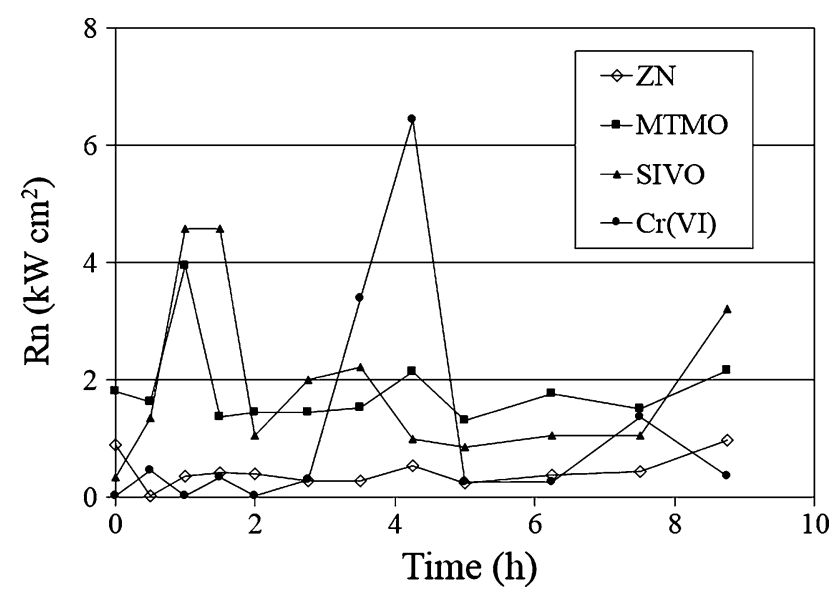

Fig. 10 Noise resistance of blanks and pre-treated samples against time most efficient. MTMO and Cr(VI), again, showed similar performances.

The impedance module $|Z|$ at low frequencies was selected to evaluate the corrosion behavior of the different samples. $|Z|$ was considered as the total resistance of the system (Ref 2226). In Fig. 6, the evolution of $|Z|$ as a function of immersion time, is shown. It can be seen that SIVO showed the highest impedance values during the whole test (16 h). Consistent with the corrosion rate and polarization resistance values shown in Fig. 5, ZN samples gave the lowest $|Z|$ values, while the corresponding to MTMO and Cr(VI) samples were very similar among themselves.

Figure 7 illustrates, as an example, the coupling current EN spectra obtained for $\mathrm{Cr}(\mathrm{VI})$ samples after $60 \mathrm{~min}$ of immersion. The original data were corrected in order to remove the DC tendency. EN tests showed that $E_{\text {corr }}$ and the coupling current density values of all the samples are very similar. $E_{\text {corr }}$ took values around $-1.0 \mathrm{~V}$ (Fig. 8) and $J \sim$ -0.02 to $-0.08 \mathrm{mAcm}^{-2}$ (Fig. 9). Noise resistance values $\left(R_{\mathrm{n}}\right)$ for MTMO and SIVO were around $1 \mathrm{k} \Omega \mathrm{cm}^{2}$ (Fig. 10) indicating, in general, a low barrier capacity for the pretreatments. The values of $R_{\mathrm{n}}$ for the $\mathrm{ZN}$ and $\mathrm{Cr}(\mathrm{VI})$ samples were, in general, slightly lower $\sim 0.3 \mathrm{k} \Omega \mathrm{cm}^{2}$ but in the case of $\mathrm{Cr}(\mathrm{VI})$ some peaks appeared due to the dynamic behavior of the surface. The corrosion products formed on the surface caused at the beginning a decrease in $R_{\mathrm{n}}$ values, and afterwards were able to block the defects increasing finally $R_{\mathrm{n}}$ values.

After $\mathrm{EN}$ tests in $0.05 \mathrm{~mol} / \mathrm{L} \mathrm{NaCl}$ solution all the samples presented localized corrosion. ZN samples exhibited the most corroded surface, followed by $\mathrm{Cr}(\mathrm{VI})$ and MTMO in the same level, while SIVO remained almost intact (Fig. 11).
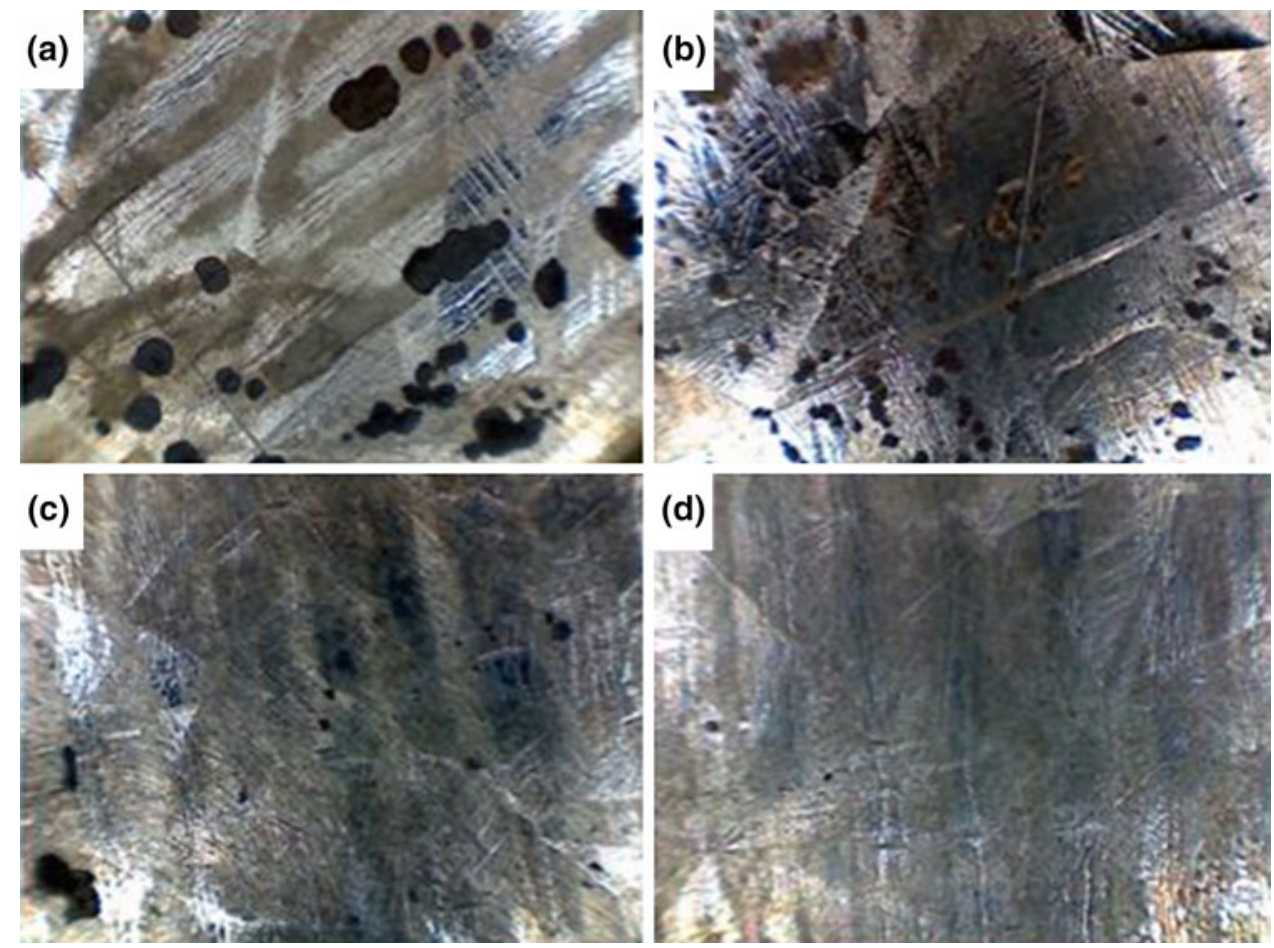

Fig. 11 OM images $(\times 200)$ after $24 \mathrm{~h}$ of immersion in $\mathrm{NaCl} 0.05 \mathrm{~mol} / \mathrm{L}$ (a) ZN, (b) $\mathrm{Cr}(\mathrm{VI}),(\mathrm{c}) \mathrm{MTMO}$, (d) SIVO samples 


\section{Conclusions}

Copper sulfate solution immersion test, CV, PC, EIS, and EN proved to be a powerful and complementary set of experimental techniques to evaluate $\mathrm{FP}$ and protective behavior of conversion and passivation coatings deposited on HDGS sheets.

The best temporary anticorrosive protection of the HDGS sheets was afforded by the SIVO conversion layer followed by MTMO and the conventional $\mathrm{Cr}(\mathrm{VI})$, which showed very similar behavior. The best performance of the SIVO film was attributed to its lower porosity that provides higher barrier effect to the ions permeation.

The HDGS corrosion type in the tested electrolytes was localized due to the diffusion of the corrosive species through structural defects of the conversion film.

The EN technique proved to be sensitive only through noise resistance values and, from this point of view, the obtained results agreed with those coming from the other electrochemical tests.

Compared with those of the conventional chromate-based film, the results for silane films are encouraging and indicative that they are an environmentally friendly alternative to be used as an eventual replacement.

\section{Acknowledgment}

The authors thank the Comisión de Investigaciones Científicas de la Provincia de Buenos Aires (CICPBA), the Consejo Nacional de Investigaciones Científicas y Técnicas (CONICET), and the Universidad Nacional de La Plata (UNLP) by the financial support to carry out the present research paper. The authors also thank to Bernardo Browne and Andrés Campbell from Camsi-X for the silanes to do this research.

\section{References}

1. Toxicological Profile for Chromium, Agency for Toxic Substances, U.S. Public Health Service, Report No. ASTSDR/TP-88/10

2. W.E.G. Hansal, S. Hansal, M. Pölzler, A. Kornherr, G. Zifferer, and G.E. Nauer, Investigation of Polysiloxane Coatings as Corrosion Inhibitors of Zinc Surfaces, Surf. Coat. Technol., 2006, 200, p 3056-3063

3. B.C. Dave, X.K. Hu, Y. Devaraj, and S.K. Dhali, Sol-Gel-Derived Corrosion-Protection Coatings, J. Sol Gel Sci. Technol., 2004, 32(1-3), p 143-147

4. S. Ono, H. Tsuge, Y. Nishi, and S. Hirano, Improvement of Corrosion Resistance of Metals by an Environmentally Friendly Silica Coating Method, J. Sol Gel Sci. Technol., 2004, 29(3), p 147-153

5. X.F. Yang, D.E. Tallman, V.J. Gelling, G.P. Bierwagen, L.S. Kasten, and J. Berg, Use of a Sol-Gel Conversion Coating for Aluminum Corrosion Protection, Surf. Coat. Technol., 2001, 140, p 44-50

6. J.H. Osborne, Observations on Chromate Conversion Coatings from a Sol-Gel Perspective, Prog. Organ. Coat., 2001, 41, p 280-286
7. A. Conde, J. De Damborenea, A. Duran, and M. Menning, Protective Properties of a Sol-Gel Coating on Zinc Coated Steel, J. Sol Gel Sci. Technol., 2006, 37, p 79-85

8. U. Bexell and T.M. Grehk, A Corrosion Study of Hot-Dip Galvanized Steel Sheet Pre-treated with $\gamma$-Mercaptopropyltrimethoxysilane, Surf. Coat. Technol., 2007, 201, p 4734-4742

9. U. Bexell, T.M. Grehk, M. Olsson, and U. Gelius, XPS and AES Characterization of Hydrolysed $\gamma$-Mercaptopropyltrimethoxysilane Deposited on Al, Zn and Al-43.4Zn-1.6Si Alloy-Coated Steel, Surf. Interface Anal., 2004, 36(7), p 624-631

10. U. Bexell and M. Olsson, Time-of-Flight SIMS Characterization of Hydrolyzed Organofunctional and Non-organofunctional Silanes Deposited on A1, Zn and Al-43.4Zn-1.6Si Alloy-Coated Steel, Surf. Interface Anal., 2003, 35(11), p 880-887

11. Dynasylan SIVO160® technical sheet. http://www.dynasylan.com

12. T. Titz, F. Hörzenberger, K. Van der Bergh, and G. Grundmeier, Correlation of Interfacial Electrode Potential and Corrosion Resistance of Plasma Polymer Coated Galvanized Steel. Part 2: Influence of Forming Induced Defects, Corros. Sci., 2010, 52, p 378-386

13. M. Dattilo, Polarization and Corrosion of Electrogalvanized Steel-Evaluation of Zinc Coatings Obtained from Waste-Derived Zinc Electrolytes, J. Electrochem. Soc., 1985, 132, p 2557-2561

14. P.R. Roberge, R. Beaudoin, and V.S. Sastri, Electrochemical Noise Measurements for Field Applications, Corros. Sci., 1989, 29(10), p $1231-1233$

15. J.R. Kearns, J.R. Scully, P.R., Roberge, D.L. Reichert, J.L. Dawson (Eds.), Electrochemical Noise Measurements for Corrosion Applications, ASTM, STP 1277, USA, 1996, p 39-58

16. R.A. Cottis, Interpretation of Electrochemical Noise Data, Corrosion, 2001, 57(3), p 265-287

17. F. Huet, Electrochemical Noise Technique, in Analytical Methods in Corrosion Science and Engineering, P. Marcus, F. Mansfeld, Ed., CRC Taylor \& Francis, USA, 2005, p 507-570

18. Y. Tan, S. Bailey, and B. Kinsella, The Monitoring of the Formation and Destruction of Corrosion Inhibitor Films Using Electrochemical Noise Analysis (ENA), Corros. Sci., 1996, 38(10), p 1681-1695

19. S. Mabbutt, D.J. Mills, and C.P. Woodcock, Developments of the Electrochemical Noise Method (ENM) for More Practical Assessment of Anti-corrosion Coatings, Prog. Org. Coat., 2007, 59, p 192-196

20. L. Jiang, M. Wolpers, P. Volovitch, and K. Ogle, An atomic Emission Spectroelectrochemical Study of Passive Film Formation and Dissolution on Galvanized Steel Treated with Silicate Conversion Coatings, Surf. Coat. Technol., 2012, 206(13), p 3151-3157

21. D. Zhu and W.J. van Ooij, Enhanced Corrosion Resistance of AA 2024-T3 and Hot-dip Galvanized Steel Using A Mixture of Bis[triethoxysilylpropyl]tetrasulfide and bis-[trimethoxysilylpropyl]amine, Electrochim. Acta, 2004, 49, p 1113-1125

22. G. Barceló, M. Sarret, and C. Müller, Corrosion Resistance and Mechanical Properties of Zinc Electrocoatings, Electrochim. Acta, 1998, 43, p 13-20

23. M.W. Kendig, H.S. Ryang, T.I. Liao, and S.I. Jeanjaquet, Comparison of Corrosion Protection Provided by a Non-Volatile Organic Compound Epoxy and a Marine Epoxy Primer, Corrosion, 1999, 55(24), p 222-228

24. E. Almeida, L. Fedrizzi, and T.C. Diamantino, Oxidising Alternative Species to ChromiumVI, in Zinc-galvanised Steel Surface Treatment. Part 2-An Electrochemical Study, Surf. Coat. Technol., 1998, 105(1-2), p $97-101$

25. A.A.O. Magalhaes, I.C.P. Margarit, and O.R. Mattos, Electrochemical Characterization of Chromate Coatings on Galvanized Steel, Electrochim. Acta, 1999, 44(24), p 4281-4287

26. M.-N. Chen, X.-B. Lu, Z.-H. Guo, and R. Huang, Influence of Hydrolysis Time on the Structure and Corrosion Protective Performance of (3-Mercaptopropyl)triethoxysilane Film on Copper, Corros. Sci., 2011, 53, p 2793-2802 